\title{
Degradation of pectic polysaccharides in forage chicory (Cichorium intybus L.) by rumen bacteria
}

\author{
X.Z. Sun ${ }^{1,2,5}$, S.O. Hoskin ${ }^{1}$, K.N. Joblin ${ }^{2}$, I.G. Andrew ${ }^{3}$ \\ and P.J. Harris ${ }^{4}$ \\ ${ }^{1}$ Institute of Veterinary, Animal and Biomedical Sciences, Massey University \\ Palmerston North, New Zealand \\ ${ }^{2}$ Grasslands Research Centre, AgResearch, Palmerston North, New Zealand \\ ${ }^{3}$ Institute of Molecular Biosciences, Massey University, Palmerston North, New Zealand \\ ${ }^{4}$ School of Biological Sciences, The University of Auckland, Auckland, New Zealand
}

\begin{abstract}
In vitro degradation of fresh chicory (L.) leaves were studied using rumen bacteria Lachnospira multiparus (pectinolytic) and Fibrobacter succinogenes (cellulolytic). L. multiparus did not release cellulose- and "hemicellulose"-associated monosaccharides glucose, xylose or mannose, but released the rhamnogalacturonan-associated monosaccharides arabinose, galactose and rhamnose, and rapidly released homogalacturonan-associated monosaccharides uronic acids. F. succinogenes also released uronic acids extensively, but at a slower rate than L. multiparus and also released glucose, xylose and mannose. F. succinogenes released these monosaccharides sequentially in the order uronic acid, rhamnose, and then arabinose and galactose together, suggesting that pectic polysaccharides degrade faster than cellulose and "hemicelluloses", among pectic polysaccharides homogalacturonan faster than rhamnogalacturonan I. It appears the degradation of pectic polysaccharides by rumen bacteria may contribute significantly to the high digestibility of forage chicory.
\end{abstract}

KEY WORDS: pectic polysaccharides, chicory, degradation, Lachnospira multiparus, Fibrobacter succinogenes, homogalacturonan

\section{INTRODUCTION}

In our previous study, an analysis of structural polysaccharides in the cell walls of chicory (Cichorium intybus L.) leaves showed an abundance of pectic polysaccharides, predominantly homogalacturonan (Sun et al., 2006). Pectic polysaccharides accounted for 67 and $58 \%$ of the total wall polysaccharides in the

\footnotetext{
${ }^{5}$ Corresponding author: e-mail: xuezhao.sun@agresearch.co.nz
} 
laminae and midribs, respectively. Pectin-associated monosaccharide residues in chicory cell walls are mainly uronic acid (UA), arabinose (Ara), galactose (Gal) and rhamnose (Rha) (Sun et al., 2006). UA is associated mainly with homogalacturonan (HG), Ara, Gal and Rha mainly with rhamanogalacturonan I (RG I).

During an investigation into chicory as a forage for ruminants (Hoskin et al., 1995; Kusmartono et al., 1997; Burke et al., 2000), the breakdown of pectic polysaccharides received little attention. Recently, treatment of chicory leaves with endopolygalacturonase suggested that the rapid ruminal particle breakdown of chicory may be attributed to degradation of HG by pectinolytic enzymes (Sun et al., 2007). However, studies on the degradation of pectic polysaccharides in chicory by rumen bacteria are lacking. Therefore, we conducted an incubation study with rumen bacteria to investigate the bacterial degradation of pectic polysaccharides.

\section{MATERIAL AND METHODS}

\section{Plant material}

Chicory (cv Puna II) plants were grown in a glasshouse for 4 weeks and then outdoors for 4 weeks. The first to the third expanded leaves (about $20 \mathrm{~cm}$ in length $\times 4 \mathrm{~cm}$ in width), as described in Sun et al. (2006), were harvested and immediately used for experiments.

\section{Rumen bacteria}

The pectinolytic bacteria Lachnospira multiparus D32 and the cellulolytic bacteria Fibrobacter succinogenes S85 were selected for study. The bacteria were obtained from the culture collection of the Rumen Microbiology Unit at AgResearch Grasslands, Palmerston North (New Zealand).

\section{Incubation media}

The anaerobic techniques of Hungate (1969) were used in the preparation of media, inoculation and incubation. The basal anaerobic medium (BY) was based on that of Joblin et al. (2002). The medium was boiled under $\mathrm{O}_{2}$-free $\mathrm{CO}_{2}$ for 3-5 min, cooled under $\mathrm{O}_{2}$-free $\mathrm{CO}_{2}$ by immersing in an ice bath and L-cyst-HCl added. The medium $(10 \mathrm{ml})$ was dispensed into $\mathrm{CO}_{2}$-filled Hungate tubes (Bellco Biotechnology, Vineland, NJ) and autoclaved for $20 \mathrm{~min}$ at $15 \mathrm{psi}\left(121^{\circ} \mathrm{C}\right)$. Before incubation, vitamin solution (0.1 ml) prepared after Joblin et al. (2002) was added anaerobically and aseptically to each culture tube. 
Weight loss and monosaccharide residue release

To prepare tissues for fermentation tests, chicory leaves were washed with tap water and distilled water and dried with tissue to remove surface water. The midrib and the lamina were separated and both tissues were cut transversely into $3 \mathrm{~cm}$ long pieces. After the samples were accurately weighed (fresh weight about $500 \mathrm{mg}$ ), they were transferred into pre-weighed tubes, and the tubes were flushed with $\mathrm{O}_{2}$-free $\mathrm{CO}_{2}$ for $10 \mathrm{~min}$.

For sterilization, plant tissues were treated with an anaerobic solution of penicillin and streptomycin (Joblin, 1981). BY medium $(10 \mathrm{ml})$ and a solution of penicillin and streptomycin $(0.1 \mathrm{ml})$ were added anaerobically and aseptically to each tube under $\mathrm{O}_{2}$-free $\mathrm{CO}_{2}$, and the tubes kept at $39^{\circ} \mathrm{C}$ for 3 days. The antibiotic solution was removed aseptically and anaerobically by syringe and replaced with $8 \mathrm{ml} \mathrm{BY}$ medium. After $24 \mathrm{~h}$, the solution was removed and the wash process repeated a further 2 times with $10 \mathrm{ml}$ BY medium.

The samples were then inoculated with rumen bacteria and incubated at $39^{\circ} \mathrm{C}$, together with uninoculated tubes as controls. Before inoculation, inoculates were washed twice by centrifuging in a bench centrifuge at $1,100 \mathrm{~g}$ for $15 \mathrm{~min}$ for the removal of carbohydrates in the sub-culture medium.

Cultures were incubated for specified times $(0,24,72 \mathrm{~h})$ and were then centrifuged at $1,100 \mathrm{~g}$ for $15 \mathrm{~min}$. The samples were washed twice with $10 \mathrm{ml}$ distilled $\mathrm{H}_{2} \mathrm{O}$ by centrifugation, then the residues were freeze dried and stored in a desiccator over $\mathrm{P}_{2} \mathrm{O}_{5}$.

After weighing, the residue was analysed for uronic acid and neutral monosaccharide residues after hydrolysing, as described in Sun et al. (2006).

The net losses of dry weight, uronic acid and neutral monosaccharide residues were calculated from the differences between values before and after degradation. ANOVA analyses were performed using GenStat v 9.1.

\section{RESULTS}

In uninoculated control cultures, $47 \pm 2 \%$ of lamina and $53 \pm 3 \%$ of midrib by dry weight was solubilized during pre-treatment with antibiotics and during incubation. This soluble material was excluded in the calculation of net weight loss from inoculated samples. The insoluble weight in the uninoculated control after pre-treatment was set as the weight before degradation. The mean net weight losses from chicory leaf lamina and midrib after incubation for 24 and $72 \mathrm{~h}$ with the two bacterial species are shown in Table 1.

After $24 \mathrm{~h}$ incubation, a substantial amount of chicory dry materials was released by L. multiparus in contrast to F. succinogenes $(\mathrm{P}<0.05)$. After $72 \mathrm{~h}$ incubation, $F$. 
succinogenes solubilized $19 \%$ of lamina and $54 \%$ of midrib, whereas L. multiparus solubilized $41 \%$ of both lamina and midrib.

UA was released from both the lamina ( $40 \%$ of UA) and midrib ( $60 \%$ of UA) in the first $24 \mathrm{~h}$ of L. multiparus incubation. After $72 \mathrm{~h}$ incubation, only $3-4 \%$ of UA remained. Loss of UA from chicory tissues was greater with L. multiparus compared with $F$. succinogenes $(\mathrm{P}<0.01)$.

With $24 \mathrm{~h}$ incubation, galactose, arabinose and rhamnose were released in large amounts by L. multiparus, but were not released by F. succinogenes until after 72 $\mathrm{h}$ incubation when partial release occured. Even after $72 \mathrm{~h}$ incubation, release by L. multiparus was greater than by F. succinogenes $(\mathrm{P}<0.05)$.

After $72 \mathrm{~h}$ incubation xylose, mannose and glucose were not released from chicory tissues by L. multiparus, in contrast to F. succinogenes $(\mathrm{P}<0.01)$.

Table 1. Loss of dry materials, uronic acids (UA) and neutral monosaccharide residues from chicory lamina and midribs after 24 and $72 \mathrm{~h}$ incubation with bacteria, $\%$

\begin{tabular}{lcccc}
\hline Cell-wall & \multicolumn{2}{c}{ Lachnospira multiparus } & \multicolumn{2}{c}{ Fibrobacter succinogenes } \\
\cline { 2 - 5 } components & lamina & midrib & lamina & midrib \\
\hline 24 h incubation & & & & \\
dry materials & $10.1 \pm 5.9$ & $27.2 \pm 3.3$ & $7.3 \pm 1.8$ & $3.4 \pm 2.5$ \\
uronic acids & $39.0 \pm 7.8$ & $59.1 \pm 3.3$ & $11.5 \pm 2.6$ & $17.4 \pm 4.2$ \\
rhamnose & $1.0 \pm 4.1$ & $29.5 \pm 3.7$ & $\operatorname{tr}$ & $\operatorname{tr}$ \\
arabinose & $\operatorname{tr}$ & $41.6 \pm 8.7$ & $\operatorname{tr}$ & $2.2 \pm 5.9$ \\
xylose & $2.3 \pm 3.7$ & $2.6 \pm 7.7$ & $\operatorname{tr}$ & $\operatorname{tr}$ \\
mannose & $1.9 \pm 1.7$ & $1.4 \pm 1.6$ & $1.6 \pm 2.6$ & $7.3 \pm 8.0$ \\
galactose & $17.6 \pm 8.8$ & $26.7 \pm 7.8$ & $\operatorname{tr}$ & $0.5 \pm 8.9$ \\
glucose & $7.7 \pm 1.4$ & $1.2 \pm 5.5$ & $8.9 \pm 3.5$ & $\operatorname{tr}$ \\
72 h incubation & & & & \\
dry materials & $41.3 \pm 2.7$ & $41.0 \pm 3.8$ & $19.2 \pm 0.8$ & $53.5 \pm 0.3$ \\
uronic acids & $97.2 \pm 0.1$ & $96.1 \pm 0.6$ & $31.5 \pm 7.8$ & $68.0 \pm 1.8$ \\
rhamnose & $61.7 \pm 9.0$ & $50.3 \pm 8.0$ & $23.2 \pm 3.0$ & $61.6 \pm 7.2$ \\
arabinose & $75.7 \pm 0.1$ & $79.0 \pm 6.6$ & $20.4 \pm 13.9$ & $51.6 \pm 3.7$ \\
xylose & $\operatorname{tr}$ & $\operatorname{tr}$ & $20.9 \pm 5.2$ & $55.2 \pm 0.4$ \\
mannose & $7.3 \pm 0.4$ & $\operatorname{tr}$ & $6.8 \pm 8.9$ & $60.8 \pm 0.8$ \\
galactose & $74.0 \pm 2.1$ & $59.5 \pm 6.8$ & $18.6 \pm 15.3$ & $55.3 \pm 3.1$ \\
glucose & $4.9 \pm 5.8$ & $\operatorname{tr}$ & $32.0 \pm 6.6$ & $59.1 \pm 2.7$ \\
\hline
\end{tabular}

mean $\pm \operatorname{SEM}(n=4) ;$ tr, trace (less than 0.5$)$

\section{DISCUSSION}

This study has shown that more UA, Ara, Gal and Rha residues were released in comparison to other monosaccharide residues, suggesting that the pectic polysaccharides were degraded preferentially. UA was also released faster than 
neutral monosaccharide residues. This is probably because most UA was in the form of weakly bound (CDTA and $\mathrm{Na}_{2} \mathrm{CO}_{3}$ soluble) HG (Sun et al., 2006), hence easily accessible to L. multiparus enzymes. Although only 3-4\% of UA remained, much Ara (24-28\%), Gal (26-28\%), Rha (28-38\%) were not released, suggesting that the pectinolytic enzymes of $L$. multiparus may have had limited ability to degrade RG I. L. multiparus is known to secrete pectate lyase (Silley, 1985), but other pectinolytic enzymes have not been reported.

The current findings with single bacterial species are also consistent with Hatfield and Weimer (1995) who reported that pectic polysaccharides were more readily and more completely degraded by mixed ruminal bacteria than other wall polysaccharides. In this study, pectin-associated monosaccharide residues were released more from the midrib by F. succinogenes than by L. multiparus. Osborne and Dehority (1989) reported that F. succinogenes secrete enzymes degrading alkali-extractable polysaccharides, cellulose and pectins. They found that when either the cellulolytic bacterium F. succinogenes or the "hemicellulolytic" bacterium Bacteroides ruminicola were co-cultured with the pectinolytic bacterium $L$. multiparus, pectin degradation from orchard grass (Dactylis glomerata) was greater than that with $L$. multiparus alone. This suggests that the degradation of pectins may be facilitated by the degradation of other wall components. RG I is possibly bound to cellulose (Sun et al., 2006). Therefore, cellulose degradation may result in increased release of neutral pectic monosaccharide residue by F. succinogenes.

The converse may also be true where degradation of other wall polysaccharides may be affected by the degradation of pectic polysaccharides. Sun et al. (2007) showed that degradation of polysaccharides by endogalacturonanase reduced chicory to small particles, hence increasing the surface area of forage particles. Pectic polysaccharides are considered to combine physically with the cellulose-xyloglucan in a model of the primary cell walls of dicotyledons (McCann and Robert, 1991). Pectic polysaccharides control the pore size of the cell wall matrix. Since pectic polysaccharides were degraded faster and more extensively than other wall polysaccharides in forages such as lucerne (Hatfield and Weimer, 1995) and chicory (this study), the space inside the network of cellulose and xyloglucan may increase after the release of polysaccharides, and, as a result, the surface area for attack by bacteria might increase. Thus the degradation of cellulose and xyloglucan would be facilitated. From synergistic effects found between cellulolytic and pectinolytic enzymes during sugar beet pulp saccharification, cellulose degradation was suggested to be prevented by a barrier of pectic polysaccharides (Spagnuolo et al., 1997). So the possibility for pectin degradation facilitating the degradation of other wall polysaccharides remains.

Based on the above, a hypothesis regarding the degradation of polysaccharides in the nonlignified primary walls of dicotyledonous forages by bacteria in the rumen can be proposed. In these walls, HG would be degraded first and then give access for rumen bacteria to attack the cellulose-xyloglucan network. 
Degradation of cellulose-xyloglucan would then facilitate the further degradation of polysaccharides, mainly RG I. The hypothesis is illustrated as follows:

HG degradation $\rightarrow$ cellulose-xyloglucan degradation $\rightarrow$ RG I degradation

\section{CONCLUSIONS}

Pectic polysaccharides of forage chicory appear to be degraded by rumen bacteria faster and to a greater extent than other wall polysaccharides. Homogalacturonans appear to be degraded faster than RG I. Possible synergistic effects between degradation of pectic polysaccharides and other wall polysaccharides may exist whereby degradation of HG facilitates degradation of the cellulose-xyloglucan network with subsequent degradation of other cell wall polysaccharides.

\section{REFERENCES}

Burke J.L., Waghorn G.C., Brookes I.M., Attwood G.T., Kolver E.S., 2000. Formulating total mixed rations from forages - defining the digestion kinetics of contrasting species. Proc. N.Z. Soc. Anim. Prod. 60, 9-14

Hatfield R.D., Weimer P.J., 1995. Degradation characteristics of isolated and in situ cell-wall lucerne pectic polysaccharides by mixed ruminal microbes. J. Sci. Food Agr. 69, 185-196

Hoskin S.O., Stafford K.J., Barry T.N., 1995. Digestion, rumen fermentation and chewing behavior of red deer fed fresh chicory and perennial ryegrass. J. Agr. Sci. 124, 289-295

Hungate R.E., 1969. A roll-tube method for cultivation of strictanaerobes. In: Methods Microbiology, 3b, pp. 117-132

Joblin K.N., 1981. Isolation, enumeration, and maintenance of rumen anaerobic fungi in roll tubes. Appl. Environ. Microbiol. 42, 1119-1122

Joblin K.N., Matsui H., Naylor G.E., Ushida K., 2002. Degradation of fresh ryegrass by methanogenic co-cultures of ruminal fungi grown in the presence or absence of Fibrobacter succinogenes. Curr. Microbiol. 45, 46-53

Kusmartono, Shimada A., Barry T.N., 1997. Rumen digestion and rumen outflow rate in deer fed fresh chicory (Cichorium intybus) or perennial ryegrass (Lolium perenne). J. Agr. Sci. 128, 87-94

McCann M.C., Roberts K., 1991. Architecture of the primary cell wall. In: C.W. Lloyd (Editor). The Cytoskeletal Basis of Plant Growth and Form. Academic Press, London, pp. 109-129

Osborne J.M., Dehority B.A., 1989. Synergism in degradation and utilization of intact forage cellulose, hemicellulose, and pectin by 3 pure cultures of ruminal bacteria. Appl. Environ. Microbiol. 55, 2247-2250

Silley P., 1985. A note on the pectinolytic enzymes of Lachnospira multiparus. J. Appl. Bacteriol. 58, $145-149$

Spagnuolo M., Crecchio C., Pizzigallo M.D.R., Ruggiero P., 1997. Synergistic effects of cellulolytic and pectinolytic enzymes in degrading sugar beet pulp. Bioresource Technol. 60, 215-222

Sun X.Z., Andrew I.G., Joblin K.N., Harris P.J., McDonald A., Hoskin S.O., 2006. Polysaccharide compositions of leaf cell walls of forage chicory (Cicorium intybus L.). Plant Sci. 170, 18-27

Sun X.Z., Hoskin S.O., Andrew I.G., Joblin, K.N., Harris P.J., 2007. In vitro degradation of forage chicory (Cicorium intybus L.) by endopolygalacturonase. J. Sci. Food Agr. (in press) 